\title{
Analysis of the Effect of Sloshing on Damage Stability after the Addition of LNG Tanks
}

\author{
Agoes Santoso $^{1}$, Achmad Baidowi², Mardisuin Siahaan ${ }^{3}$ \\ (Received: 01 January 2019 / Revised: 05 August 2020 / Accepted: 31 August 2020)
}

\begin{abstract}
The Damage Stability, better known as leaky ship stability, is a condition where the vessel has a leak in the ship's compartment so that the stability condition of the ship is disrupted. This study is a study of the effects caused by sloshing on the stability of the ship. The method used to calculate damage stability is the lost buoyancy method. This method assumes a condition where when the vessel has a leak, the vessel buoyancy will decrease. This happens because the empty space in the vessel will be filled with water, so it is no longer the part that contributes to the buoyancy so that the ship will increase and can result in sinkage. According to the calculation of SOLAS (Safety of Life at Sea) Consolidated Edition 2014 Chapter II-1 Part B-1. There are two indexes compared, namely index Required index $R=0.77172$, which depends on the length of the lining and Attained subdivision index $A=0.83736$. The pi factor shows a maximum of 5 leak zones that can be overcome by the ship to remain stable. By comparing the index value of $A>R$, it can be seen that this ship has fulfilled the SOLAS requirements.
\end{abstract}

Keywords—damage stability, probabilistic, lost buoyancy, sloshing.

\section{INTRODUCTION}

\section{$\mathrm{S}$}

hip stability performance is influenced by two main

factors, that are: 1 . The shape of the hull of the ship and, 2. Load distribution on board. The first factor is the constant value of ships that have been completed, while the second factor can change at each loading and unloading condition depending on the type of cargo carried by ship. A kind of change in certain load distribution can occur due to sloshing that occurs in partially filled tanks. Sloshing is a phenomenon of fluid free movement in a partially filled container which gives a free surface effect (FSE). When the tanks on board are half full, rolling and pitching the ship makes the liquid in the tank move towards the movement of the ship. This effect is known as an FSE.

Damage stability, better known as leaky ship stability, is a condition in which the ship has a leak in the ship's compartment. The ship's ability to maintain the buoyancy of the ship is reduced so that the stability of the ship becomes disrupted. This condition must be overcome by having a compartment plan that is able to prevent instability or even cause the ship to get a grounding. The method is used to calculate damage stability is the lost buoyancy method. This method assumes a condition where when the vessel has a leak. The vessel buoyancy will decrease. This happens because the empty space in the vessel will be filled with water so that it is no longer the part that contributes to the buoyancy so that the ship will increase and can result in sinkage [1].

In accordance with the calculation of SOLAS (Safety of Life at Sea) Consolidated Edition 2014

Agoes Santoso is with Departement of Marine Engineering, Institut Teknologi Sepuluh Nopember, Surabaya, 60111, Indonesia. E-mail: agoes@its.ac.id

Achmad Baidowi is with Departement of Marine Engineering, Institut Teknologi Sepuluh Nopember, Surabaya, 60111, Indonesia. Email: ahmadbai@gmail.com

Mardisuin Siahaan is with Departement of Marine Engineering, Institut Teknologi Sepuluh Nopember, Surabaya, 60111, Indonesia. Email: mardisuinsiahaan@gmail.com
Chapter II-1 Part B-1. There are two indexes compared, namely index R Required index, which depends on the length of the sealing and index A Attained subdivision index.

The index A value depends on the pi factor, which indicates the possibility that the compartments or some of the related compartments have a leak and the factor that indicates the possibility of the ship surviving in the event of a leak. By comparing index $\mathrm{A}$ and index $\mathrm{R}$ values, it can be seen whether damage stability and ship insulation have met SOLAS standards. Therefore, this research will analyze the movement of sloshing in the LNG tank, which is related to stability when the condition of the hull of the ship has leaked. With the sloshing analysis, it will be known that it will affect the new intact stability and damage stability condition, whether it meets the requirements of SOLAS Consolidated Edition 2014 Chapter II-1 Part B-1 [5].

\section{METHOD}

\section{A. Characteristics of Ro-Ro Ferry}

Ro-Ro (Roll On - Roll Off) is a type of passenger ship that can be used to transport passengers as well as vehicles. The ro-ro ship has a ramp door that works open and closes mechanically to load vehicles connected directly to the pier. The ramp on ro-ro ships is usually made on the stern, bow, or side of the ship equipped with system lashing to prevent cargo loads vehicles shifting when sailing in bad weather. As one of the modes of transportation that are widely used to connect regions in Indonesia, ro-ro vessels are an important concern for ship safety given the many ro-ro ship accidents in Indonesia. According to the safety aspects of ro-ro vessels, there are several considerations that make ro-ro ships more likely to experience accidents, including (a). stability problem, (b). low freeboard, (c). door access charge, (d). absence of bulkhead, (e). location of high safety equipment, (f). sensitive to weather conditions, 
(g). binding of truckloads, and (h). loading process that affects heavy distribution [2].

The movement of the ship on the surface of the water is always insulated. The different types of isolated movements experienced by ships can be described in six types of vessel movement conditions, three of which are linear movements and three rotational movements at three vertices, including (a). surging, (b). Swaying, (c). Heaving, (d). Rolling, (e). Pitching, (f). Yawing. In order to find out the sloshing movements that occur in the tank, it is necessary to know how the characteristics of wave movements that cause the movement of the ship. Waves are defined as changes in shape due to the movement of the water surface. In order to keep the load transfer on board does not occur freely. Then the lashing system is carried out. The Lashing system is a vehicle binding system loaded on the ship so that the vehicle remains in its position on when the ship sails.

The ramp door is the door used as a bridge between the dock and the ship. The ramp door is generally located at the bow or stern of the ship. It will open down to load the vehicles to enter the ship. When the ramp door opens, the vehicle from the dock can get on board. And when the ship sailed, the ramp will be closed. In this study, this ship has a length of 99.20 meters. The service speed of this vessel is 17 knots supported by double engines 2300 HP. This ship can carry 856 passengers and 30 crews with maximum vehicles, 26 units trailer 40", two units tronton truck, 56 medium trucks, and 36 cars.

\section{B. Ship stability theory}

Stability can be interpreted as the ship's ability to return to its original state after being subjected to external forces. This ability is influenced by the dynamic arm (GZ), which forms a coupling moment that balances the upward compressive force with gravity. The component of stability consists of GZ, KG, and GM. In calculating stability, the most important thing is to find the price of the dynamic arm (GZ), then after the GZ price is obtained, it is checked by "intact stability code, IMO" [1].

There are two calculations of stability for ships that are intact stability and damage stability. Intact stability is a calculation of the stability of the ship for (not leaky), which is calculated on several tank conditions for each degree of slope of the ship. An intact stability calculation is done to determine the ability of the ship to return to its equilibrium position after experiencing a heel. In comparison, damage stability is a leaky ship calculation (damage), which is calculated on several conditions for each degree of slope. The damage stability calculation is carried out to determine the ability of the ship to hold the leak in order to remain stable when the ship's hull is damaged or leaking.

In calculating leakage, experts used the deterministic approach method, meaning that in carrying out calculations, one or two compartments will be determined in advance, so the volume of incoming water is considered meaningless compared to the displacement of the ship. And also has been determined the consequences that will arise that is shaking that occurs no more than 6 (initial stability), and the maximum waterline after leaking is a margin line (a line that is a distance of 3 "under the strength deck).

The above approach is now no longer usable because the reality is that it cannot be determined which compartment is experiencing leakage and how the consequences will occur. A new approach is used, which is closer to the reality in the field, namely a probabilistic approach. Has introduced a probability notation of ships that can survive after the leakage, and the method is known as 'a new way.' This approach carries out a calculation that covers all the possible cases of leakage along with the ship that could occur along with the possibility of a leak case that could be one, two, three, or more compartments that are close together. So with this method, the configuration of the entire location of a longitudinal or transverse bulkhead can be declared able to survive or not to make the ship survive if it experiences flooding or leakage without the need to calculate the distance per bulkhead [1].

\section{Basic understanding of flooding}

The ship is a floating building composed of iron and steel plates. The vessel has compartments or tankhandles. If the ship's shell is damaged, it will cause seawater to enter the room or compartment of the ship. This goes on until a new balance occurs from the ship or until the ship itself sinks due to conceding water. In practice, it is impossible to make a ship that is truly able to survive to not leak (flooding) either due to accidents, run aground, or other causes. Therefore, the naval architect strives as much and optimally as possible to reduce the sinking of the ship due to flooding both in terms of construction and regulations and standard shipping. The standard regulation governing the leakage of this ro-ro vessel is SOLAS about Subdivision and Damage Stability [1].

\section{Flooding and Damage Condition}

Damage stability is the condition of the stability of the ship that suffered hull damage, to an extent not larger than defined by pertinent regulations, should continue to float and be stable under moderate environmental conditions. Flooding of adjacent compartments also can be more dangerous than the flooding of two non-adjacent compartments [1].

The method is used to calculate the damage stability is the Lost buoyancy method. The principle of this method of calculation is that when the vessel has a leak, the room that has been admitted to water is no longer considered a part of the ship. Because the ship's parts are reduced, the buoyancy or the upward force is also reduced. Reduced buoyancy, the sinkage will occur, which will cause the ship to rise.

\section{RESULT AND DISCUSSION}

\section{A. Calculation of SOLAS Requirements}

The SOLAS regulation on subdivision is intended to get the minimum bulkhead distance for ships that still affect safety standards. Fulfilling or not a subdivision of 
one ship is placed by a subdivision degree $(\mathrm{R})$ index for passenger ships defined as the equation below

$$
\mathbf{R}=1-\frac{5,000}{L s+2.5 N+15.225}
$$

Where :

$$
\begin{aligned}
& \mathrm{N} \quad=\mathrm{N}_{1}+\mathrm{N}_{2} \\
& \mathrm{~N}_{1} \quad=\text { Total passengers to be covered by lifeboats } \\
& \mathrm{N}_{2} \quad=\text { Total passengers \& Crew that are allowed on } \\
& \text { board exceed } \mathrm{N}_{1} .
\end{aligned}
$$

The index of the subdivision index achieved (Attained Subdivision Index, A) of a ship must not be less than the price of index R. Index A is calculated based on the equation below:

$$
\mathbf{A}=\mathbf{\Sigma P i} \mathbf{S i}
$$

Where :

i: Shows compartments or groups of compartments that are close together and are considered to be leaky and contribute significantly to the value of A.

Pi: Calculation results (values) that indicate the probability/probability that the selected compartment (i) will be able to leak.

Si: Calculation results (values) that indicate the probability of the possibility of a ship surviving After the selected compartment (i) has a leak.

This calculation must cover all cases that may occur along with the ship (Ls), which contributes to the value of index A. This case can occur for one compartment or several compartments that are close together. If there is a wing compartment, the calculation must also include this compartment. This compartment can be a case of own flooding and can also be a combination of compartments in it. If there is an elongated bulkhead, the calculated case is a case of leakage on one side of the ship, which results in the heeling. If there is a longitudinal bulkhead that is located right at the centerline, it is considered to have never been damaged.

\section{B. Ship motion}

In calculating ship movements in this final project using seakeeper software. Maxsurf seakeeper software. The ship model is imported into the seakeeper software in calm water because the analysis coefficients have not been included. Once imported, the frame of reference is used, which is useful for hydrostatic characteristics of the ship's movements. There are several data inputs, namely:

\section{- Measure Hull}

Measure hull is used to divide the ship into several frames. By default, all surfaces will be measured and divided into 11 equal parts. This is sufficient for initial calculations, but for more accurate predictions, the number of parts must increase to between 15 and 30. This is needed for parts that are very wide or deep and have a low cross-sectional area due to mapping calculations may not be accurate. So that the greater the area to be measured, the more accurate the calculation will be.

\section{- Vessel Type}

Because this ship is a single hull ship, the chosen option is a single hull.

\section{- Mass Distribution}

In order to determine the movement, the seakeeping requires mass distribution data in the form of percent of ship length and ship width. In a seater for ships with a single hull shape, the default value of the pitch gyration is between $25 \%$ Loa, and the roll gyration is between $35 \%-40 \%$ of the ship width.

- Damping factor

The response of the roll damping is calculated based on the hydrostatic properties of the ship. Roll damping is almost entirely due to the effect of viscosity, which is not modeled by the seakeeper. The general value for most vessels is 0.1-0.5. Lewis 1989 gave a value of 0.05 for a typical ship without roll damper equipment.

\section{- Environment}

In this menu is the density of the ship's cruise fluid, namely the density of seawater 1.025 tons / $\mathrm{m} 3$.

\section{- Seakeeping range}

Seakeeper automatically calculates the frequency range to predict the RAO of a ship. However, a number of steps where the RAO is calculated may be determined by the user. The greater the value, the prediction of the point where the RAO calculation will roughly be more accurate. But because this ship will be simulated on a regular wave, this option is left with a default of 21 from the seakeeper.

- Analysis Method

This menu displays the methods used in analyzing the wave of ships to be used. Because this ship has a transom, the selected part is the transom terms. Then select salve and arbitrary wave heading because the waves that will be accumulated are regular waves and head facing angles.

\section{- Solving}

Before using this menu, we recommend that the data obtained in the form of the desired ship heading, ship speed, wave period, and wave amplitude inputted on the windows menu then select Windows input. While the way to add input to each tab table is by selecting edit - add. In this final assignment, the input will be in the form of a ship speed of 17 knots, with a heading angle of $180 \mathrm{o}$ and input spectra using the DNV and Jonswap methods with the data obtained with a maximum wave and a wave period. If Windows input is inputted properly, then solving can already be run.

- Calculate wave surface

$$
\omega_{\mathrm{e}}=\frac{2 \pi}{\lambda}(\mathrm{c}-\mathrm{U} \cos \mu)
$$

After the encounter frequency is obtained, regular waves are chosen by calculating the encounter frequency and wave amplitude. Whereas to display regular 
waveforms is on the display-animate menu. So that the results of the regular movement output on the sea keeper with the selected encounter frequency.

The ship's motion characteristics are presented in the RAO graph (Response Amplitude Operator). RAO is a transfer function that is used to determine the effect of sea conditions on the movement of the ship. So from there, it can be known whether a ship needs a design change to improve stability. The use of RAO in the design phase of a ship makes it possible to determine the modifications needed in the design to meet safety criteria and to improve the performance of the ship. RAO shows the trend of ship movements against waves.

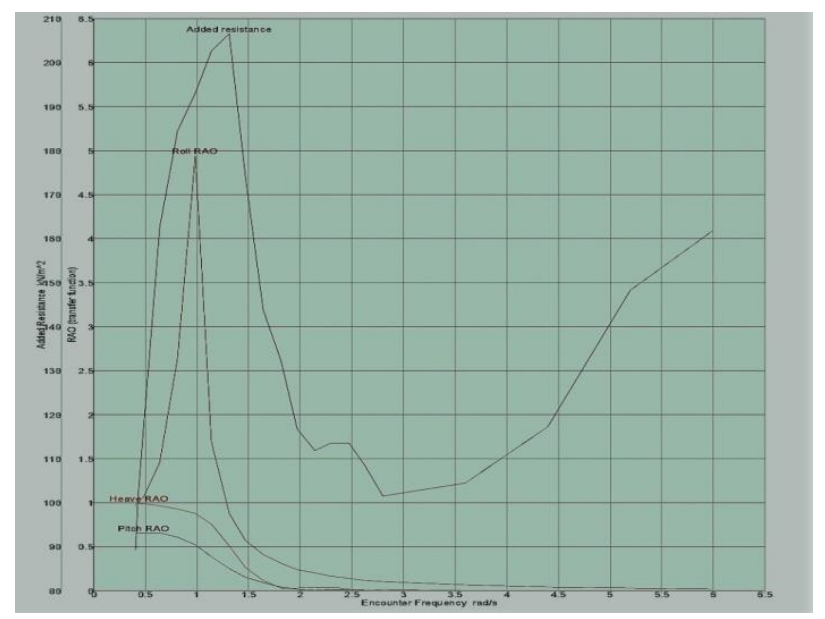

Figure. 1. Graph of RAO

Analysis of ship movement response is done by comparing the motion response that occurs in several cases of loading when the intact condition. Resonance analysis is only performed on three types of movements, namely heave, roll, and pitch. There were five loading cases in this study, namely the first case of the lightship draft. The second case is the ballast condition. The third case is the full load. The fourth case is the full arrival. The fifth case is a partial load.

\section{Intact stability}

Stability analysis in this study can be done by calculating the righting moment and the heeling moment due to wind. Calculation of the return moment for a small slope angle $\left(<15^{\circ}\right)$ uses the equation below:

$M_{R}=$ Righting moment (ton.m)

$\Delta=$ displacement (ton)

$G M=$ Height of metacenter on $\mathrm{G}(\mathrm{m})$

$\theta=$ Heeling angle $(\mathrm{deg})$

The intact stability calculation is done with the help of MaxSurf stability software. After inputting the load case, then the running analysis process can be done to determine the heeling moment in each ship loading condition, which are: a. LWT load case, b. Load case Ballast, c. Load case Full load, d. Load case Full Arrival and e. Load case Partial load.

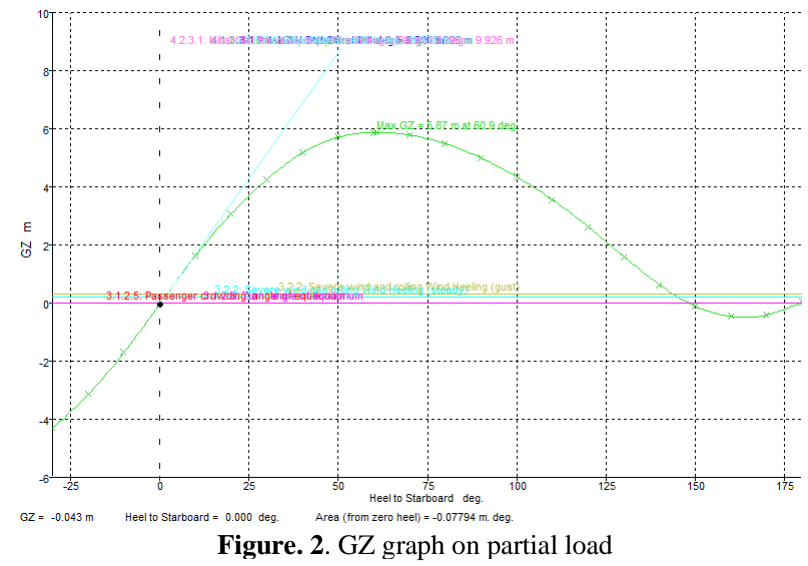

From the five loading conditions above, the smallest value of the stability parameter is the partial load condition. This is because the daily tank on the ship decreases during the voyage while the load carried by vessel is settled, resulting in a change in the new center of gravity.

After knowing the pressure on the tank, the next step is to analyze the LNG tank calibration on Maximum

\section{Sloshing on LNG Tanks}

Sloshing is a phenomenon of fluid movement inside a container or tank, which is partially filled. This effect is called as FSE (free surface effect). In order to simulate the sloshing phenomenon, this study used software Ansys fluent. 
stability to determine the effect of the sloshing force on

(FSM). the ship so that it can know Free Surface Moment

TABLE 1.

FREE SURFACE MOMENT EFFECT

\begin{tabular}{|c|c|c|c|c|c|c|c|c|}
\hline \multirow[t]{2}{*}{ Tank Name } & \multirow{2}{*}{$\begin{array}{l}\text { Sounding }(\mathrm{m}) \\
(\mathrm{m})\end{array}$} & \multirow{2}{*}{$\begin{array}{l}\text { Ullege } \\
\text { (m) }\end{array}$} & \multirow{2}{*}{$\begin{array}{l}\% \text { Full } \\
\mathrm{m}^{\wedge} 3\end{array}$} & \multirow{2}{*}{$\begin{array}{c}\text { Capacity } \\
\text { (m) }\end{array}$} & LCG & $\mathrm{TCC}$ & \multirow{2}{*}{ VCG } & \multirow[t]{2}{*}{ FSM } \\
\hline & & & & & (m) & (m) & & \\
\hline \multirow[t]{3}{*}{ Gas Tank } & 4.6 & 0.36 & $75 \%$ & 39.77 & 10.58 & 7.12 & 4.16 & 40.56 \\
\hline & 4.0 & 0.96 & $50 \%$ & 32.75 & 10.74 & 6.62 & 3.70 & 27.13 \\
\hline & 3.4 & 1.58 & $25 \%$ & 25.73 & 11.14 & 6.38 & 3.05 & 12.41 \\
\hline
\end{tabular}

The table above shows that with the addition of the LNG tank, it will contribute to the effect of the moment, which is a free sure moment, which determines the stability of the ship. With variations in filling level conditions a). 25\%: 12,410 tons .m b). 50\%: 27,138 tons .m c). 75\%: 40,563 tons .m.

\section{E. Damage simulation preparation}

The damage zone is determined between each transverse bulkhead, the distance between which is
To calculate and determine the index value of $R$, in the table also allows us to reduce the value of $\mathrm{R}$ to adjust the calculation of the value of index R in SOLAS 2014 Consolidated Edition Chapter II-1 part B-1 About Subdivision and Damage Stability of Cargo and Passenger Ship. Because from software calculations it can be seen that index $\mathrm{R}$ is greater than the value of $\mathrm{R}$ index in manual calculations, the value of index $R$ is reduced to match the actual value

measured by a tank arrangement and with the position of Zone 1 starts from the stern ship.

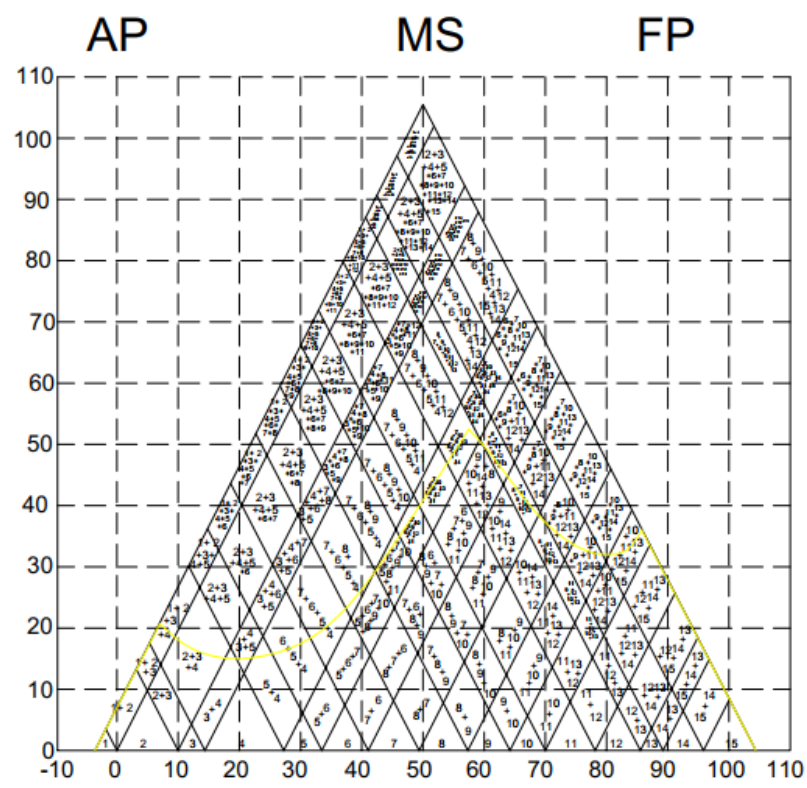

Figure. 3. Triangle of damage probabilistic

Based on the tank arrangement, it can also be determined the longitudinal position of the bulkhead in each zone, with the position of the value 0 being the width of the cap, the Longitudinal Bulkhead position is obtained in each zone as follows:

Likewise on the deck position in each zone, where the double bottom is also considered as a deck so that the table is obtained as follows

From the calculations, it is known that the length of the leakage for longitudinal $=5.76 \mathrm{~m}$, the length of the leakage transverse $=3.2 \mathrm{~m}$, and the length of the vertical leakage from baseline to infinity.

\section{F. Damage assumption}

In the scenario of leakage, damage occurs on the tank, compartment, and double base. So for the room between the impermeable bulkhead in the picture above (void tanks, ballast tanks) is considered to be one compartment. Making damage cases is done by filling tab damage cases by creating a new case with the name in accordance with the leaked compartment. After all, has been prepared, the software will do the calculation automatically to get the factor p-value as shown below: The value of factor $p$ is the result of a calculation (value), which indicates the probability / longitudinal probability 
that the selected compartment (i) can leak. This value is influenced by the number of transverse bulkheads.

Then the value of factor $r$ is obtained, as shown below:

The value of $r$ factor is the result of a calculation of the value that shows the probability in transversely that the selected compartment (i) can be leaked. This value is influenced by the number and distance of the longitudinal bulkhead.

And the last $\mathrm{v}$ factor value is obtained, which can be seen in the picture below:

The value of factor $\mathrm{v}$ is the result of a calculation (value), which indicates the probability/probability of being vertical that the selected compartment (i) can be leaked. This value is influenced by the number and distance of the deck bulkhead.

After being able to find out the above is done running for analysis of damage stability by clicking on Maxsurf Stability, the Maxsurf software will analyze the stability of each case from heel $-30^{\circ}$ to $180^{\circ}$ calculated for each increase of $10^{\circ}$ with the heel direction to the part port. This analysis produces values from several things that are included in a calculation table that we will use to

TABLE 2

\begin{tabular}{llll}
\multicolumn{3}{c}{ A VALUE } \\
\hline $\begin{array}{l}\text { Number of } \\
\text { Adjacent zone } \\
\text { To consider }\end{array}$ & Condition & A factor \\
\hline & & & \\
& & & \\
& $\begin{array}{l}\text { Deepest } \\
\text { Subdivision Draft }\end{array}$ & (As) & 0.78164 \\
& $\begin{array}{l}\text { Partial subdivision } \\
\text { Draft (Ap) } \\
\text { Ballast service draft } \\
\text { attained } 0.82101\end{array}$ & \\
& Subdivision index \\
& \multicolumn{2}{c}{ MSC.216(82) } & \\
\hline
\end{tabular}

TABLE 3.

RECAPITULATION OF A > R

\begin{tabular}{lcc}
\multicolumn{2}{c}{ RECAPITULATION OF A > R } \\
\hline Condition & $\begin{array}{c}\text { A factor } \\
\text { (p.r.v.s) }\end{array}$ & Required (R) \\
\hline $\begin{array}{l}\text { Deepest } \\
\text { Subdivision Draft (As) }\end{array}$ & \\
$\begin{array}{l}\text { Partial subdivision } \\
\text { Draft (Ap) }\end{array}$ & 0.83736 & 0.77172 \\
Ballast service draft & \\
\hline
\end{tabular}

determine the damage stability analysis of these values

- Index A

- Index S

- Comparison of index A and R

- Value of immersion angle

- Value of range degree

- GZ max

- Equilibrium angle degree

- $\quad$ The angle of vanishing stability degree

- GZ max angle

- K-value

After getting the damage stability analysis table, the recapitulation of the table data can be done to facilitate reading the results of the analysis. The SOLAS regulation on subdivision is intended to get the minimum tight insulation for ships that still affect safety standards. With the results of the Maxsurf Stability software analysis, the results are as shown below
In the table above, it can be seen that one leakage zone value $A$ has fulfilled the $A>R$ ratio as required by the 2014 SOLAS Consolidated Edition Chapter II Part B-1 regarding Subdivision and damage stability.

\section{G. Floodable length analysis}

Floodable length is the curve of leakage or curve of the maximum length between the watertight bulkhead or the maximum length of the compartment in the vessel (i.e., the maximum allowable length so that when a compartment has a leak). 


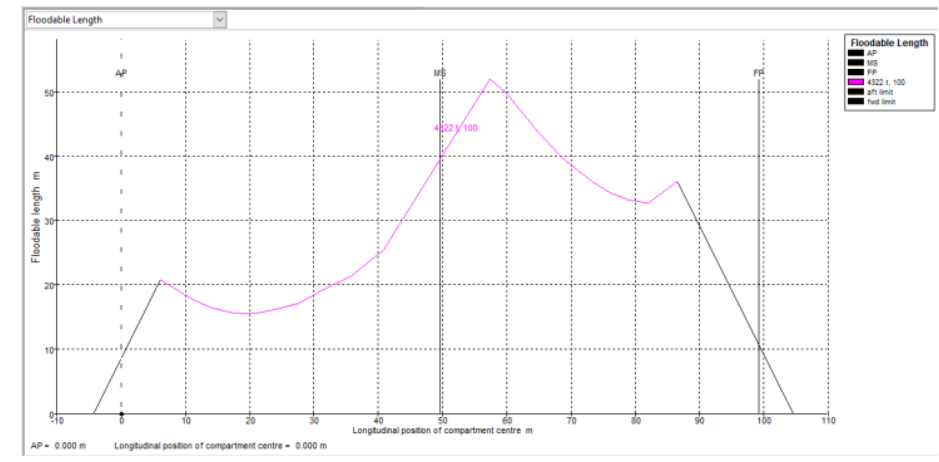

Figure. 4. Floodable length

The above curve shows the maximum length of allowable sealing in the event of a leak.

\section{CONCLUSION}

From the results of the analysis of the effect of sloshing on the stability of the ship when experiencing a leak, it can be concluded that:

1) In this final project, the damage stability of a Ro-Ro Ferry 5000 GT has been calculated. Calculating the damage stability on this ship has complied with SOLAS chapter II-1 part B-1 regulations regarding subdivision and damage Stability of Cargo and Passenger ships. This can be seen from the results of the calculation of index $\mathrm{A}=0.83736$, which is greater or equal to the calculation of the index subdivision value $\mathrm{R}$ $=0.77172$ required by SOLAS. Because of the value of $A>R$, the division of the bulkhead on the Ro-Ro Ferry has met SOLAS requirements.

2) Based on the regulation of the IGF code, the arrangement of LNG tanks should be on an open deck with considerations as below:

- LNG tanks should be placed not less than B/5 of ship's breadth

- LNG tanks should be separated by cofferdam with the minimum of thickness is $900 \mathrm{~mm}$ insulated by steel plate class A-60

- Tanks have to be preserved by drip trays. It has to be stainless steel or other materials which is standing on a low temperature or cryogenic materials, and it has to be covered by separated construction to the deck in order to escape its construction from the damage.

3) The maximum leaky compartment that the RoRo ferry can still hold is up to five leaky compartments. The factor $\mathrm{p}$-value for more than five leakage zones is below the minimum factor p-value, so analysis cannot be performed.

4) The stability condition of the ship changes this can be seen from the curve of the return arm or righting lever (GZ) in each loading condition (Load case).
5) Drying the moment of sloshing due to the LNG tank with variations in filling level conditions are:
a). 25\%: 12,410 tons .m
b). 50\%: 27,138 tons. $\mathrm{m}$
c). $\sim 75 \%: 40,563$ tons .m

6) The stability conditions of each loading are Load case 1. The Ballast Condition (GZ) is 82.7 degrees before the addition of the LNG tank and becomes 73.6 after the addition of the LNG tank. Load case 2. The partial load condition (GZ) is 76.4 degrees before the addition of the LNG tank and becomes 70 degrees after the addition of the LNG tank. Load case 3. The Full Load condition (GZ) is 68.2 degrees before the addition of the LNG tank and becomes 63.6 degrees after the addition of the LNG tank. 
International Journal of Marine Engineering Innovation and Research, Vol. 5(3), Sept. 2020. 164-171 (pISSN: 2541-5972, eISSN: 2548-1479)

\section{REFERENCES}

[1]. A. Biran, Ship Hydrostatics and Stability, Oxford: Butterworth-Heinemann, 2003.

[2]. Dokkum V. Klass "Ship Knowledge a Modern Encyclopedia" Dokmar, Netherlands, 2003.

[3]. N.A. Cakasana and D. Manfaat, " Analisis Damage Stability pada Desain awal FSO untuk lapangan minyak kakap di Laut Natuna Provinsi Kepulauan Riau," Reopsitory ITS, 2017.

[4]. MSC.391(95)," Adoption of International Code of Safety for Ships Using Gases or other Low-Flashpoint Fuels (IGF Code)," June 2015

[5]. S.K.I.K.P. KNKT, "Capaian kinerja investigasi keselatan tranportasi tahun 2017," Jakarta, 2017.

[6]. SOLAS Consolidated Edition 2014 Sixth Edition, United Kingdom, July 2014.

[7]. YA Pratama and E. Djatmikom "Sloshing simulation on Three Types TankShip on Pitching and Heaving motion," International Journal of Marine Engineering Innovation and Research, pp 175-188,2017. 